\title{
Novas ocorrências de macroalgas marinhas bentônicas no estado de Pernambuco, Brasil ${ }^{1}$
}

New records of benthic marine macroalgae from Pernambuco state, Brazil ${ }^{1}$

\author{
Luanda Pereira Soares ${ }^{2,3} \&$ Mutue Toyota Fujii ${ }^{2}$
}

\begin{abstract}
Resumo
Foram realizados estudos na região entremarés de recifes da Praia de Boa Viagem, Recife, nordeste do Brasil, em dezembro de 2009 (período seco) e abril de 2010 (período chuvoso), para analisar a estrutura da comunidade das macroalgas epífitas em outras macroalgas. O material foi coletado em dois trechos recifais, cada um com aproximadamente $30 \mathrm{~m}$ de extensão, em diferentes compartimentos favoráveis ao crescimento de macroalgas. Todo o material coletado permaneceu congelado até o procedimento de análise. Os exemplares estão depositados no Herbário do Instituto de Botânica, São Paulo, Brasil (SP). Foram encontradas nove novas ocorrências para a costa pernambucana: Boodlea composita (Harv.) F. Brand, Ceramium corniculatum Mont., Chaetomorpha clavata Kütz., C. nodosa Kütz., Chondracanthus cf. saundersii C.W. Schneid. \& C.E. Lane, Cladophora laetevirens (Dillwyn) Kütz., Neosiphonia sphaerocarpa (Børgesen) M.-S. Kim \& I.K. Lee, Ulva linza L. e U. prolifera O.F. Müll. Destas, quatro tiveram sua distribuição consideravelmente ampliada ao longo do litoral brasileiro.

Palavras-chave: Chlorophyta, epífitas, costa nordeste do Brasil, Rhodophyta.
\end{abstract}

\begin{abstract}
Studies were carried out in the intertidal reefs of Boa Viagem beach, Recife, northeastern Brazil, in December 2009 (dry season) and April 2010 (rainy season), to analyze the community structure of seaweeds growing on other macroalgae. The material was collected in two areas, each around $30 \mathrm{~m}$ long, in different habitats which are suitable for the growth of seaweeds. The seaweeds remained frozen until the analysis. The specimens are deposited at the Herbarium of the Instituto de Botânica, São Paulo, Brazil (SP). Nine species were recorded for the Pernambuco coast for the first time: Boodlea composita (Harv.) F. Brand, Ceramium corniculatum Mont., Chaetomorpha clavata Kütz., C. nodosa Kütz., Chondracanthus cf. saundersii C.W. Schneid. \& C.E. Lane, Cladophora laetevirens (Dillwyn) Kütz., Neosiphonia sphaerocarpa (Børgesen) M.-S. Kim \& I.K. Lee, Ulva linza L. and U. prolifera O.F. Müll. Of these, four species had their distribution along the Brazilian coast considerably expanded.
\end{abstract}

Key-words: Chlorophyta, epiphytes, Northeastern Brazilian coast, Rhodophyta.

\section{Introdução}

O litoral pernambucano apresenta $187 \mathrm{~km}$ de extensão e está incluído na Zona Ocidental proposta por Oliveira Filho (1977), que na classificação de Horta et al. (2001) corresponde à região tropical (entre o oeste do Ceará e o sul da Bahia), caracterizada por abrigar a flora marinha mais diversificada do Brasil, com representantes típicos de regiões tropicais, principalmente estabelecida sobre recifes de arenito incrustados por algas calcárias e corais, favoráveis ao crescimento de outras algas bentônicas.

Segundo Pereira et al. (2002), nos últimos anos, a presença da poluição orgânica no litoral do estado de Pernambuco vem sendo um dos fatores mais prejudiciais para a sobrevivência das algas, principalmente em trechos da região metropolitana (Sousa \& Cocentino 2004; Simões et al. 2009). O

\footnotetext{
${ }^{1}$ Parte da dissertação de Mestrado da primeira autora.

${ }^{2}$ Instituto de Botânica, Programa de Pós-graduação em Biodiversidade Vegetal e Meio Ambiente, Núcleo de Pesquisa em Ficologia, Av. Miguel Estéfano 3687 , 04301-902, São Paulo, SP, Brasil.

${ }^{3}$ Autora para correspondência: luanda87@gmail.com
} 
fácil acesso aos ecossistemas recifais torna esses ambientes alvos da ação antrópica, sendo visitados com frequência pelos banhistas que pisoteiam os organismos que ali se encontram (Azevedo et al. 2011; Huff 2011). As comunidades marinhas sofrem os impactos da exploração descontrolada dos organismos, introdução de espécies exóticas, eutrofização, modificação de hábitats e mudanças climáticas globais (Monteiro Neto \& Mendonça Neto 2009). Desse modo, para fornecer subsídios para as políticas conservacionistas visando à exploração racional e ao manejo dos recursos naturais, estudos em tais comunidades são necessários a fim de conhecer a diversidade marinha. A última compilação de dados referentes às algas marinhas de Pernambuco foi realizada por Pereira et al. (2002), que listaram 301 táxons infragenéricos, distribuídos em 105 Chlorophyta, 43 Heterokontophyta (como Phaeophyta) e 153 Rhodophyta.

Este trabalho teve como objetivo descrever e ilustrar espécies de macroalgas não citadas anteriormente para o litoral do estado de Pernambuco.

\section{Material e Métodos}

O litoral de Pernambuco possui clima tropical quente e úmido do tipo As' (Andrade \& Lins 1971), com médias anuais de temperatura de $26^{\circ} \mathrm{C}$, com um período seco entre setembro e fevereiro e um período chuvoso de março a agosto (Kempf 1967/69). Os ventos predominantes são de sudeste (Gregório \& Araújo 2008, Rollnic et al. 2011) e as marés são semidiurnas, com amplitude máxima de 3,1 m e mínima de $-0,2 \mathrm{~m}$ (Rollnic \& Medeiros 2006). Os recifes são constituídos por embasamentos arenítico e arenítico ferruginoso (Dominguez et al. 1990), formando uma bela paisagem, de grande importância para o turismo do estado (Araújo et al. 2007).

O litoral de Pernambuco, incluindo trechos da Praia de Boa Viagem, está passando por graves problemas de erosão costeira causada principalmente pela ocupação desordenada das praias por edificações ou outras estruturas que dificultam a sedimentação (Araújo et al. 2007, Silva et al. 2008). A Praia de Boa Viagem se caracteriza como um destino turístico consolidado na região metropolitana da cidade do Recife (Silva et al. 2006), apresenta trechos altamente disputados por banhistas e comerciantes e cerca de $60 \%$ do lixo encontrado na região pertencem à categoria dos plásticos manufaturados (Dias Filho et al. 2011).
As algas foram coletadas em dezembro de 2009 (período seco) e abril de 2010 (período chuvoso) na região entre marés, em duas estações de coleta, cada uma com aproximadamente 30 $m$ de extensão: uma ao norte $\left(8^{\circ} 7\right.$ ' $15,83^{\prime}$ 'S e $\left.34^{\circ} 53^{\prime} 39,57^{\prime \prime} \mathrm{W}\right)$ e outra ao sul $\left(8^{\circ} 7^{\prime} 57,79^{\prime}\right.$ 'S e $\left.34^{\circ} 53^{\prime} 57,88^{\prime \prime} \mathrm{W}\right)$ da Praia de Boa Viagem. Durante as coletas, os recifes foram percorridos desde o lado protegido, voltado para a praia, até o lado exposto ao embate das ondas, visitando os diferentes compartimentos recifais disponíveis para o crescimento das macroalgas. $\mathrm{O}$ material coletado nestes ambientes, com auxílio de espátulas metálicas, foi acondicionado em sacos plásticos devidamente etiquetados. Todo o material foi congelado até o procedimento de análise em laboratório e, posteriormente, fixado e preservado em formol a $4 \%$ em água do mar. Quando necessário, os espécimes foram corados com solução aquosa de azul de anilina a 0,5\%, acidificada com $\mathrm{HCl} 1 \mathrm{~N}$. As fotografias e/ou fotomicrografias foram obtidas com câmera digital acoplada diretamente à ocular micrometrada do estereomicroscópio ou microscópio óptico binocular. Medidas foram realizadas em todos os indivíduos coletados, ressaltando o fato de que algumas espécies foram encontradas apenas uma vez. Após o estudo foram confeccionadas exsicatas, que estão depositadas no Herbário Maria Eneyda P. Kauffman Fidalgo (SP) do Instituto de Botânica, São Paulo. A classificação das espécies está de acordo com Wynne (2011) e os nomes dos autores dos táxons seguem Brummitt \& Powell (1992).

\section{Resultados e Discussão \\ Chlorophyta \\ Siphonocladophyceae, \\ Cladophorales, Cladophoraceae}

Chaetomorpha clavata Kütz., Bot. Zeitung 5: 166. 1847.

Fig. $1 \mathrm{a}-\mathrm{d}$

Talo verde escuro, filamentoso, unisseriado, sem ramificação, de textura firme, com até $8 \mathrm{~cm}$ de comprimento, fixo ao substrato por prolongamentos rizoidais oriundos da célula basal produzindo um disco de fixação lobado. Célula basal curva com até $500 \mu \mathrm{m}$ de comprimento e 140 $\mu \mathrm{m}$ de diâmetro na região mediana, estreita na base e alargando em direção ao ápice. Célula suprabasal com até $250 \mu \mathrm{m}$ de diâmetro. Células da região mediana quadráticas a retangulares, com até 100 $\mu \mathrm{m}$ de comprimento e $180 \mu \mathrm{m}$ de diâmetro. Paredes 


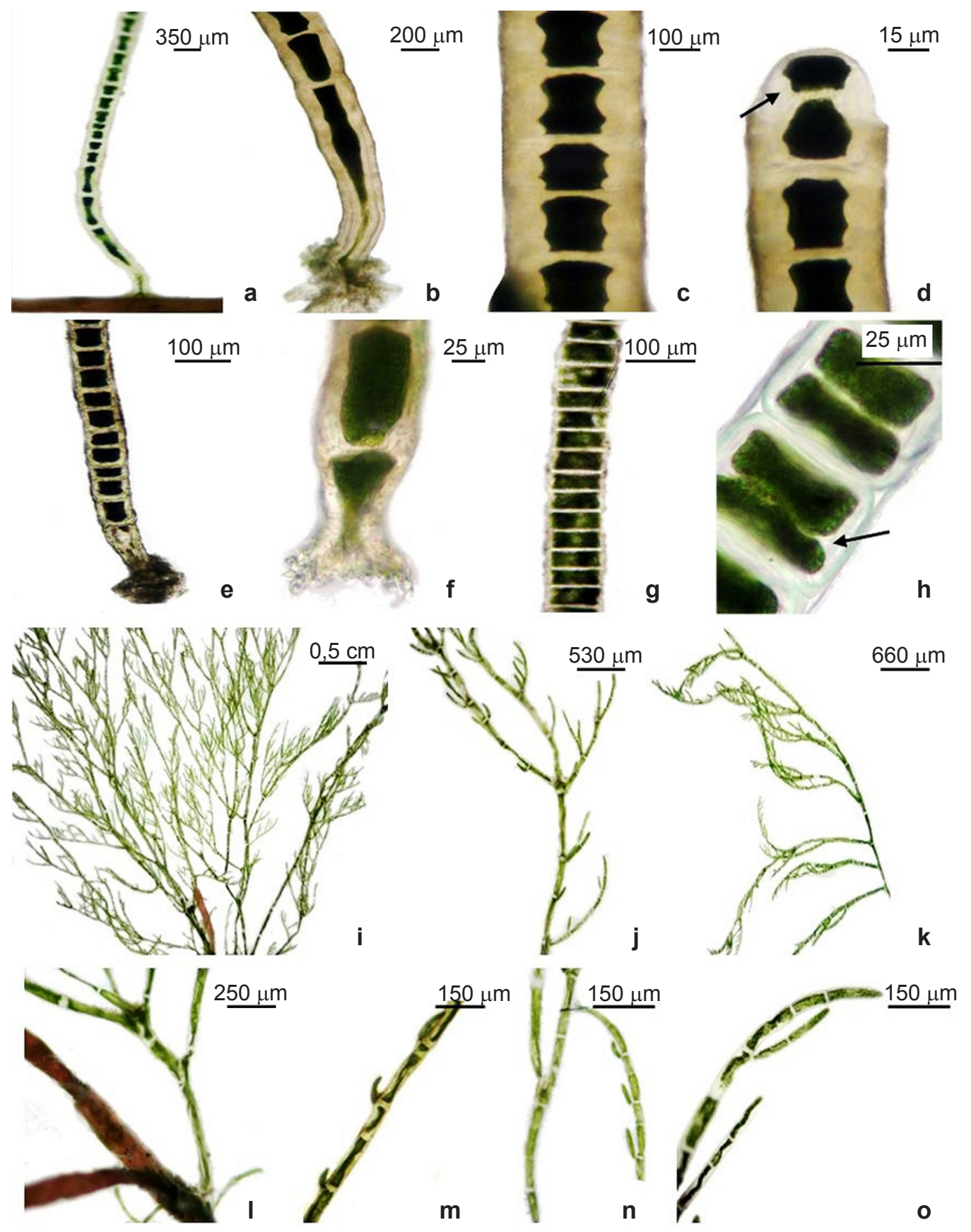

Figura 1 - Macroalgas marinhas bentônicas da Praia de Boa Viagem, Recife, Pernambuco. a-d. Chaetomorpha clavata Kütz. - a. aspecto geral do talo; b. célula basal curva; c. células mediano-apicais com paredes espessas; d. célula apical (seta). e-h. Chaetomorpha nodosa Kütz. - e. aspecto geral do talo; f. célula basal; g. células medianoapicais; h. células em divisão (seta). i-o. Cladophora laetevirens (Dillwyn) Kütz. - i. aspecto geral do talo; j. porção mediano-apical do talo; k. ramificação unilateral; 1. célula basal; m,n. ramos curtos unicelulares; o. ramo terminal falcado com célula apical.

Figure 1 - Benthic marine macroalgae from Boa Viagem beach, Recife, Pernambuco. a-d. Chaetomorpha clavata Kütz. - a. general view of the thallus; b. basal cell curvature; c. median-apical cells with thickened walls; d. apical cell (arrow). e-h. Chaetomorpha nodosa Kütz. - e. general view of the thallus; f. basal cell; g. median-apical cells; h. cell division (arrow). i-o. Cladophora laetevirens (Dillwyn) Kütz. - i. general view of the thallus; j. median-apical portion of the thallus; k. unilateral branching; 1. basal cell; m,n. unicellular short branches; o. falcate terminal branch with apical cell. 
espessas e lameladas, com até $50 \mu \mathrm{m}$ de espessura. Presença de constrições nos septos. Células férteis não foram encontradas.

Material examinado: Recife, Boa Viagem, estação norte, lado protegido do recife, 29.IV.2010, L.P. Soares et al. (SP 401172); estação sul, lado exposto do recife, 29.IV.2010, L.P. Soares et al. (SP 401173).

Espécie encontrada apenas no período chuvoso, tanto em ambientes protegidos quanto expostos às ondas, crescendo na forma de filamentos isolados sobre Chondracanthus $c f$. saundersii C.W. Schneid. \& C.E. Lane e Gelidium pusillum (Stack.) Le Jol. A presença da célula basal curva foi uma característica importante para distinguir esta espécie das demais espécies do gênero Chaetomorpha Kütz. nom. cons., assim como citado por Alves et al. (2009). Mesmo em talos jovens, nos quais essa estrutura pode ser pouco evidente, foi notada uma tênue curvatura da célula basal na região proximal.

Os exemplares analisados no presente estudo concordam com os descritos por Littler \& Littler (2000), para a região do Caribe, por apresentarem células constritas em forma de barril a intervalos regulares ao longo do talo, porém a presença de célula basal curva, característica da espécie, não é citada por estes autores. O material do Caribe apresenta talo bem mais desenvolvido, alcançando até $30 \mathrm{~cm}$ de comprimento.

A espécie distribui-se no litoral brasileiro: Paraíba (Moura 2010), Bahia (Alves et al. 2009), Abrolhos (Villaça et al. 2006), Espírito Santo (Moura 2010), Rio de Janeiro (Moura 2010).

Chaetomorpha nodosa Kütz., Spec. Algar. 376. 1849.

Fig. $1 \mathrm{e}-\mathrm{h}$

Talo verde claro a escuro, delicado, filamentoso, unisseriado, sem ramificação, com até $0,5 \mathrm{~cm}$ de comprimento, fixo ao substrato por prolongamentos rizoidais oriundos de uma pequena célula basal produzindo um disco de fixação lobado. Células em divisão intercalar observadas na metade superior dos filamentos. Célula basal reta, com até $150 \mu \mathrm{m}$ de comprimento e 50,0 $62,5 \mu \mathrm{m}$ de diâmetro na porção mediana. Célula suprabasal subcilíndrica, células mediano-apicais retangulares a quadráticas, com $25-50 \mu \mathrm{m}$ de comprimento e 60-80 $\mu \mathrm{m}$ de diâmetro. Paredes celulares espessas e lameladas com até $9 \mu \mathrm{m}$ de espessura, algumas vezes com intumescimentos. Presença de constrições nos septos. Células férteis não foram observadas.
Material examinado: Recife, Boa Viagem, 29.IV.2010, L.P. Soares et al. (SP 401174).

Espécie encontrada apenas duas vezes na região estudada, no período chuvoso e em ambiente protegido do embate das ondas, crescendo na forma de filamentos isolados nas porções apicais de Gelidium pusillum. Espécie citada pela primeira vez para o nordeste brasileiro por Alves et al. (2009). O material examinado concorda em linhas gerais com as descrições de Ugadim (1973) e Alves et al. (2009).

Distribui-se no litoral brasileiro: Bahia (Alves et al. 2009), Espírito Santo (Moura 2010), Rio de Janeiro (Falcão et al. 1992), São Paulo (Ugadim 1973), Fernando de Noronha (Széchy et al. 1989), Trindade (Nassar 1994), Martin Vaz (YoneshigueValentin et al. 2006).

Cladophora laetevirens (Dillwyn) Kütz., Phycol. General. 267. $1843 . \quad$ Fig. 1 i-o

Talo verde claro a escuro, delicado, filamentoso, com até $4 \mathrm{~cm}$ de comprimento, fixo ao substrato por rizóides oriundos da célula basal. Ramificação unilateral ou pseudodicotômica, geralmente esparsa na porção mediana do talo, tornando-se densa nas porções apicais. Ramos falcados inseridos nas porções apicais das células. Presença de vários ramos curtos unicelulares, com as extremidades afiladas, na porção mediano-apical do talo. Células do eixo principal cilíndricas, longas, com até $575 \mu \mathrm{m}$ de comprimento e 75 $\mu \mathrm{m}$ de diâmetro. Célula apical cilíndrica, com extremidade levemente afilada, com até $220 \mu \mathrm{m}$ de comprimento e $50 \mu \mathrm{m}$ de diâmetro. Células férteis não foram encontradas.

Material examinado: Recife, Boa Viagem, 2.XII.2009, L.P. Soares et al. (SP 401179); 29.IV.2010, L.P. Soares et al. (SP 401180).

Espécie com ocorrência apenas no período chuvoso, tanto no lado protegido quanto no lado exposto ao embate das ondas. Epífita de Chondracanthus cf. saundersii, Gelidium pusillum, Ceratodictyon planicaule (W.R. Taylor) M.J. Wynne e Hydropuntia caudata (J. Agardh) Gurgel \& Fredericq. A presença dos ramos curtos unicelulares na porção mediano-apical do talo mostrou ser uma boa característica para distinguir esta espécie de Cladophora dalmatica Kütz. e $C$. vagabunda (L.) C. Hoek, com as quais pode ser facilmente confundida. Hoek (1982) comenta que essas três espécies podem ser confundidas pelo formato falcado dos ramos, porém os ramos curtos 
unicelulares e as dimensões da célula apical (maior que $40 \mu \mathrm{m}$ de diâmetro) diferenciam C. laetevirens de $C$. dalmatica e $C$. vagabunda. Esta é a terceira referência da espécie para o litoral brasileiro.

Distribui-se no litoral brasileiro: Bahia (Moura 2010), Rio de Janeiro (Moura 2010).

Siphonocladophyceae, Siphonocladales, Boodleaceae

Boodlea composita (Harv.) F. Brand, Beih. Bot. Centralbl. 18: 165-193. 1904.

Fig. 2 a-k

Talo verde claro, filamentoso, unisseriado, de textura esponjosa, com até $2 \mathrm{~cm}$ de comprimento, crescendo em tufos densos, difíceis de serem retirados da macroalga hospedeira, fixo ao substrato por rizóides originados do estipe, que pode ser ou não distinto, com 154-308 $\mu \mathrm{m}$ de diâmetro. Ramificação irregular a unilateral nas porções basal e mediana do talo, tornando-se oposta nas porções apicais. Células do eixo principal na porção mediana do talo com 375-820 $\mu \mathrm{m}$ de comprimento e 100-200 $\mu \mathrm{m}$ de diâmetro. Célula apical cilíndrica, longa, com ápice arredondado com até $1.500 \mu \mathrm{m}$ de comprimento e $250 \mu \mathrm{m}$ de diâmetro. Alguns ramos, frequentemente na porção apical, com atraso na formação do septo. Presença de células tenaculares na porção apical do talo, causando a anastomose de alguns ramos. Cristais birrefringentes com formato de agulha facilmente observados sob microscópio óptico. Numerosos cloroplastos discóides com um pirenóide central, formando uma malha nas margens das células. Células férteis não foram encontradas.

Material examinado: Recife, Boa Viagem, 29.IV.2010, L.P. Soares et al. (SP 401187).

Espécie encontrada no período chuvoso e no lado exposto ao embate das ondas, formando densos emaranhados sobre Chondracanthus cf. saundersii, Gelidium pusillum e Ceratodictyon planicaule. A espécie foi referida pela primeira vez para o Brasil para a região de Cabo Frio, Rio de Janeiro, por Yoneshigue et al. (1986). Segundo Leliaert et al. (2007a), a ausência de um estipe nítido e a presença de ramificação irregular tridimensional distinguem o gênero Boodlea G. Murray \& De Toni de Phyllodictyon J. E. Gray, com o qual pode ser confundido. Yoneshigue et al. (1986) comentam que, em Boodlea, as ramificações podem aparecer em apenas um plano como em Phyllodictyon. Os membros da classe Cladophorophyceae apresentam talos sifonocladáceos (com células multinucleadas) e, tradicionalmente, são incluídos nas ordens Cladophorales e Siphonocladales, de acordo com a arquitetura do talo e o modo de divisão celular (Hoek et al. 1995; Leliaert et al. 2007b). Os limites entre as ordens e famílias de Cladophorophyceae são muito tênues, pois vários caracteres morfológicos utilizados na sua taxonomia se sobrepõem (Leliaert et al. 2003). Morfologicamente, Boodlea pertence à ordem Siphonocladales por apresentar arquitetura do talo mais complexa que os membros de Cladophorales, e estudos moleculares recentes, utilizando sequências de DNA ribossomal, confirmam essa classificação (Leliaert et al. 2007a). Segundo Wynne (2011), estas duas ordens pertencem à classe Siphonocladophyceae visto que Cladophorophyceae é um nome inválido perante o Código Internacional de Nomenclatura Botânica (McNeill et al. 2006) por não apresentar uma diagnose em latim na sua descrição original. Existe um longo debate na literatura sobre as posições taxonômicas de B. composita e Phyllodictyon anastomosans (Harv.) Kraft \& M.J. Wynne e, segundo Leliaert \& Coppejans (2007), a forma do talo e o padrão de ramificação tem sido amplamente utilizados para distinguir essas duas espécies. Boodlea composita é caracterizada pelo talo em forma de almofada e ramificação em mais de um plano, enquanto $P$. anastomosans forma lâminas com estipes e ramificação em um só plano. Contudo, os estágios juvenis dessas duas espécies são praticamente idênticos. Estudos moleculares também mostram que $B$. composita, B. siamensis Reinbold, B. montagnei (Harv. ex J.E. Gray) Egerod, P. anastomosans e Struveopsis siamensis (Egerod) P.C. Silva apresentam sequências genéticas muito próximas, indicando que estes táxons formam um complexo de espécies denominado na literatura como complexo Boodlea composita - Phyllodictyon anastomosans (Leliaert \& Coppejans 2007). Ao examinarem exemplares de diversas regiões do mundo, estes mesmos autores reconheceram sete tipos morfológicos nesse complexo com base em morfologia do talo, sistema de ramificação, divisão da célula apical, reforço do talo por células tenaculares e dimensões celulares. A ramificação oposta tanto nos ramos terminais quanto no eixo principal e o reforço estrutural do talo através de poucas células tenaculares nos permitiram identificar esta espécie como B. composita. A falta de registros desta espécie no Brasil, com ocorrência em apenas dois estados, provavelmente se deve à grande semelhança entre os gêneros Boodlea e Phyllodictyon, fazendo com que exemplares de $B$. composita fossem talvez erroneamente identificados como $P$. anastomosans, que é mais comum no litoral brasileiro. Leliaert \& 


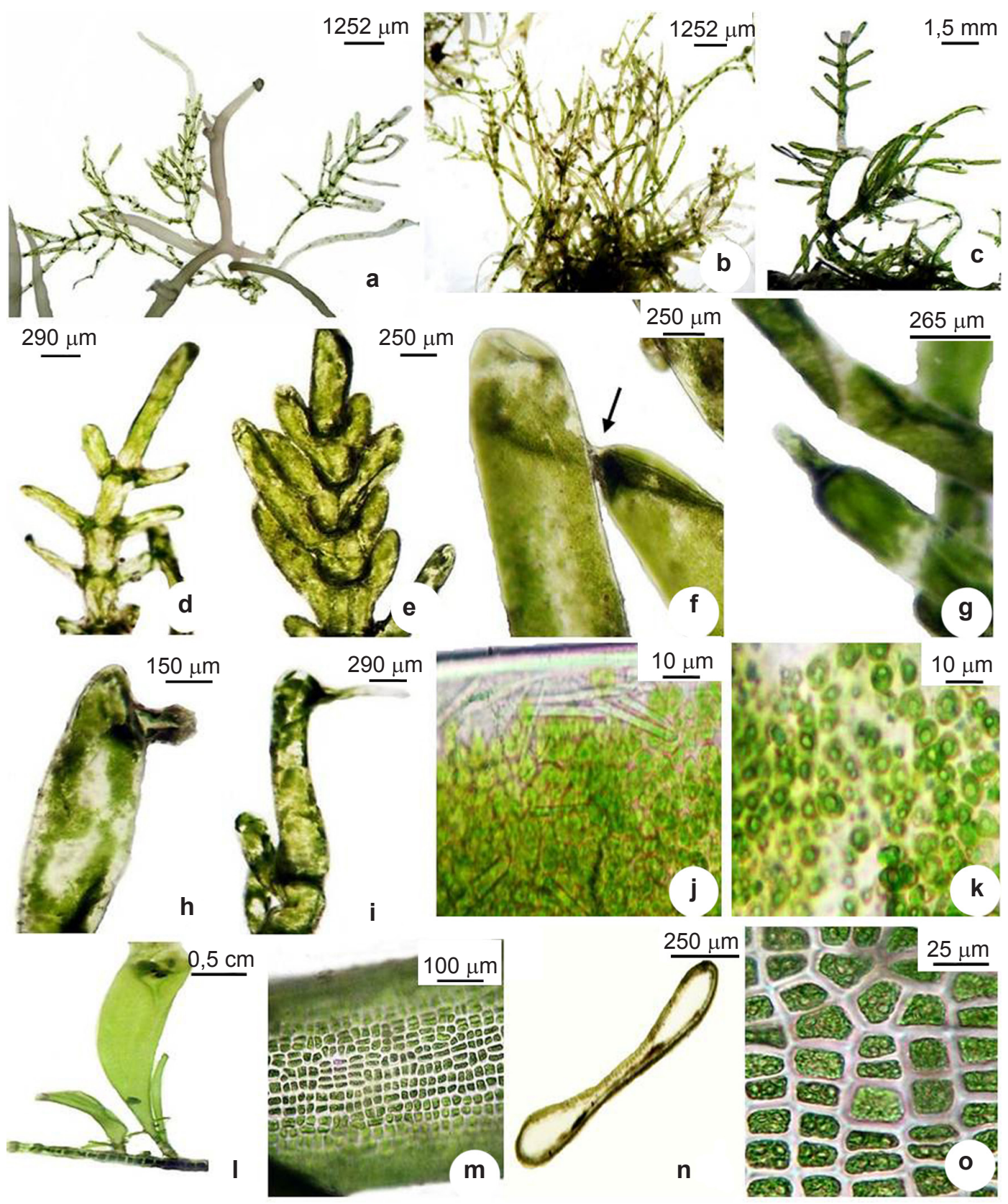

Figura 2 - Macroalgas marinhas bentônicas da Praia de Boa Viagem, Recife, Pernambuco. a-k. Boodlea composita (Harv.) F. Brand - a. aspecto geral do talo; b. padrão geral de ramificação; c. ramificação basal irregular e ramos opostos no ápice do talo; d. célula apical longa; e. células com atraso na formação dos septos; f. detalhe de uma anastomose (seta); g,h. células tenaculares; i. rizóide na porção apical do talo; j. inclusões celulares cristalinas em formato de agulha; k. cloroplastos com um pirenóide central. 1-o. Ulva linza L. - 1. exemplar crescendo sobre Chaetomorpha aerea (Dillwyn) Kütz; m. detalhe das células com discreto alinhamento longitudinal na região mediana do talo; $\mathrm{n}$. corte transversal na região mediana do talo; o. detalhe dos pirenóides.

Figure 2 - Benthic marine macroalgae from Boa Viagem beach, Recife, Pernambuco. a-k. Boodlea composita (Harv.) F. Brand. - a. general view of the thallus; b. general pattern of branching; c. irregular basal branching and opposite branches at the tip of the thallus; d. long apical cell; e. cells with delay in the formation of septum; f. detail of an anastomosis (arrow); g,h. tenacular cells; i. rhizoid at the apical portion of the thallus; j. needle-shaped crystalline cell inclusions; k. chloroplasts with a central pyrenoid. 1-o. Ulva linza L. - 1. specimen growing on Chaetomorpha aerea (Dillwyn) Kütz; m. detail of median portion of the thallus showing cells with slight longitudinal alignment; $\mathrm{n}$. cross-section from median portion of the thallus; o. detail of pyrenoids. 
Coppejans (2004) descrevem a variação morfológica das inclusões celulares cristalinas em várias espécies da classe Siphonocladophyceae (como Cladophorophyceae). Estes autores comentam que as espécies com arquiteturas do talo semelhantes, mas filogeneticamente não relacionadas, podem ser distinguidas pelos tipos de cristais que possuem. De Clerck et al. (2005) e Leliaert \& Coppejans (2007) descrevem cristais de oxalato de cálcio em formato de agulha a hexagonal presentes em todas as células do talo de $B$. composita, o que está de acordo com os encontrados no presente estudo.

Cloroplastos discóides formando uma malha nas margens das células, típicos do gênero, foram observados no presente estudo, concordando com os descritos por Yoneshigue et al. (1986).

Distribui-se no litoral brasileiro: Bahia (Moura 2010), Rio de Janeiro (Yoneshigue et al. 1986).

\section{Ulvophyceae, Ulvales, Ulvaceae}

Ulva linza L., Spec. Plant. 2: 1163. 1753.

Fig. 2 1-o

Talo verde claro, achatado, alargando-se em direção ao ápice, com até $2 \mathrm{~cm}$ de comprimento e $0,7 \mathrm{~mm}$ de diâmetro, fixo ao substrato por um pequeno apressório. Ramificações esparsas na região basal do talo. Em vista superficial do talo, células quadráticas a poligonais, com discreto alinhamento longitudinal na região mediana do talo. Em corte transversal, talo distromático com 45-60 $\mu \mathrm{m}$ de espessura, formado por duas camadas de células justapostas no centro e tubular nas margens, com células quadráticas e cloroplasto com 1-3 pirenóides. Células férteis não foram encontradas. Material examinado: Recife, Boa Viagem, 29.IV.2010, L.P. Soares et al. (SP 401192).

Espécie com ocorrência nos dois períodos do ano, tanto no lado protegido quanto no exposto ao embate das ondas. Foi encontrada como epífita de Chondracanthus cf. saundersii, Palisada perforata (Bory) K.W. Nam, Gelidium pusillum e Ceratodictyon planicaule. Embora seja uma espécie comum na área estudada e amplamente distribuída no litoral brasileiro, esta é a primeira referência na costa pernambucana, provavelmente devido ao fato de Ulva linza ser morfologicamente muito semelhante a $U$. flexuosa Wulfen e $U$. compressa L., diferenciando-se destas pelo número de pirenóides e pelo talo distromático no centro e tubular nas margens, quando visto em corte transversal. Ulva flexuosa pode apresentar em média 2 a 5 pirenóides por cloroplasto (Littler \& Littler 2000, Coto \& Pupo
2009, Pupo et al. 2011), enquanto U. compressa apresenta cloroplastos com 1 a 2 pirenóides (Littler \& Littler 2000, Coto \& Pupo 2009).

Distribui-se no litoral brasileiro: Maranhão (Ferreira-Correia et al. 1977), Ceará (PinheiroJoventino et al. 1998), Rio Grande do Norte (Câmara Neto 1971), Espírito Santo (Moura 2010), Rio de Janeiro (Gestinari et al. 1998), São Paulo (Coto \& Pupo 2009), Paraná (Ugadim 1973), Santa Catarina (Pupo et al. 2011), Rio Grande do Sul (Baptista 1977).

Ulva prolifera O. F. Müll., Icon. Plant. Florae Danicae 5(13): 8. 1778.

Fig. 3 a-d

Talo verde claro, tubular, com até $1,5 \mathrm{~cm}$ de comprimento e $1 \mathrm{~mm}$ de diâmetro na região apical do talo, fixo ao substrato por um apressório pequeno. Ramos longos e abundantes por toda a extensão do talo. Em vista superficial, células quadráticas a irregulares, com discreto alinhamento longitudinal em toda a superfície do talo. Em corte transversal, células mais altas que largas, com até $27,5 \mu \mathrm{m}$ de comprimento e $15 \mu \mathrm{m}$ de diâmetro, com cloroplasto contendo 2-6 pirenóides. Células férteis localizadas na porção apical do talo.

Material examinado: Recife, Boa Viagem, 29.IV.2010, L.P. Soares et al. (SP 401194).

Espécie com ocorrência no período chuvoso e no lado protegido do embate das ondas. Foi encontrada como epífita de Chondracanthus $c f$. saundersii, Gelidium pusillum, Ceratodictyon planicaule, Bryocladia cuspidata (J. Agardh) De Toni e Cladophora montagneana Kütz. Espécimes férteis encontrados no mês de outubro. Os exemplares encontrados neste estudo diferem dos de Coto \& Pupo (2009) pelas menores dimensões do talo e pelo maior número de pirenóides por cloroplasto. As ramificações longas e abundantes por toda a extensão do talo também são descritas por Coto \& Pupo (2009).

Distribui-se no litoral brasileiro: Bahia (Nunes 1998), Espírito Santo (Moura 2010), Rio de Janeiro (Howe 1928), São Paulo (Coto \& Pupo 2009).

$$
\begin{aligned}
& \text { Rhodophyta } \\
& \text { Florideophyceae, Gigartinales, } \\
& \text { Gigartinaceae }
\end{aligned}
$$

Chondracanthus cf. saundersii C.W. Schneid. \& C.E. Lane, Phycologia 44: 72-83. $2005 . \quad$ Fig. 3 e-i

Talo vermelho violáceo, ereto, flácido, escorregadio, com até $6,5 \mathrm{~cm}$ de comprimento, fixo ao substrato por um pequeno apressório discóide. Talo cilíndrico na porção basal, tornando- 


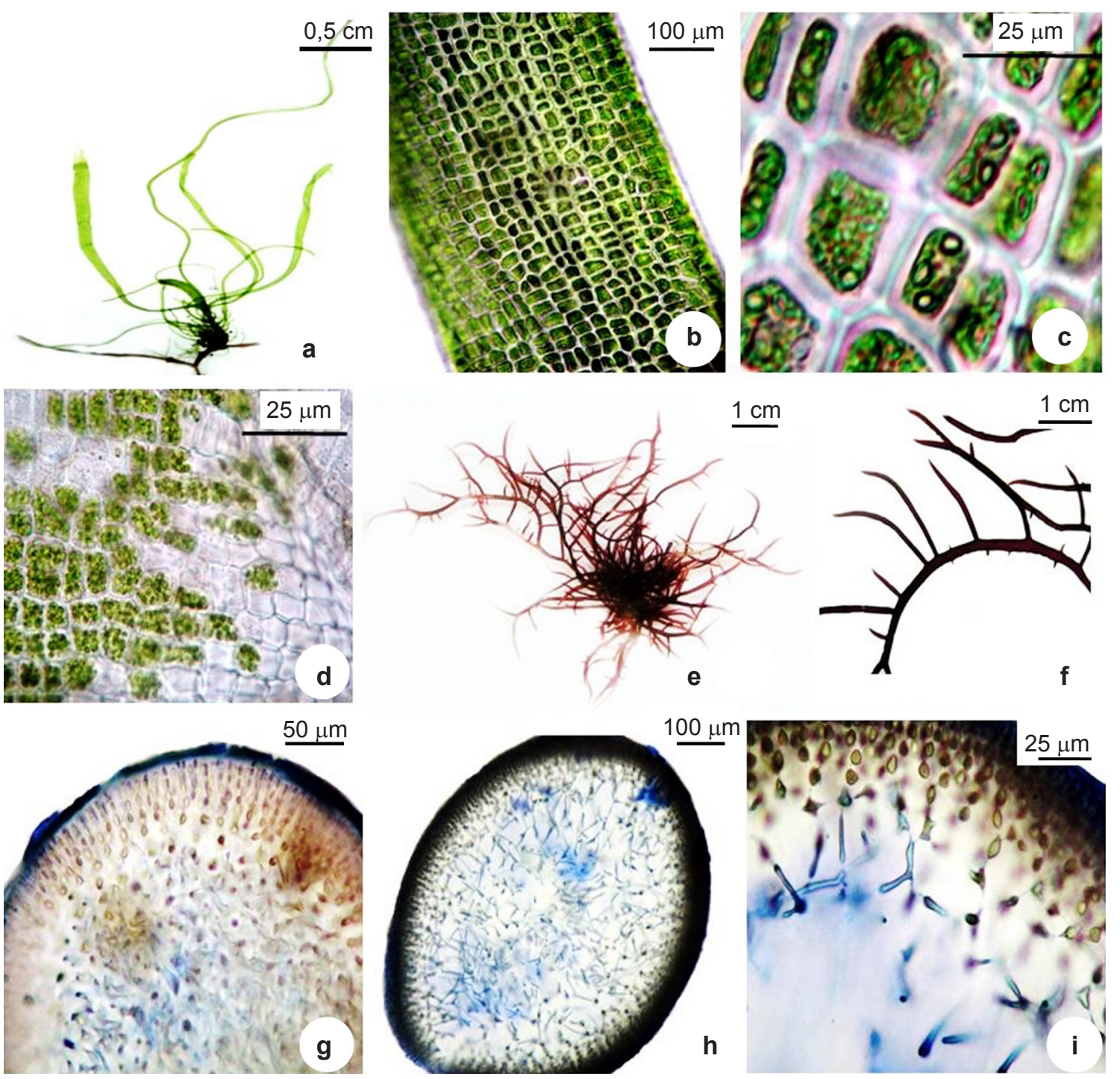

Figura 3 - Macroalgas marinhas bentônicas da praia de Boa Viagem, Recife, Pernambuco. a-d. Ulva prolifera O.F. Müll. - a. aspecto geral do talo; b. detalhe das células com discreto alinhamento longitudinal na região mediana do talo; c. detalhe dos pirenóides; d. células férteis. e-i. Chondracanthus cf. saundersii C.W. Schneid. \& C.E. Lane - e. aspecto geral do talo; f. detalhe da ramificação mostrando os ramos curvos; g. corte transversal da porção basal do talo; h. corte transversal da porção mediano-apical do talo. i. detalhe das células estreladas entre a região cortical e a região medular. Figure 3 - Benthic marine macroalgae from Boa Viagem beach, Recife, Pernambuco. a-d. Ulva prolifera O.F. Müll. - a. general view of the thallus; b. detail of the median portion of the thallus showing cells with slight longitudinal alignment; c. detail of pyrenoids; $d$. fertile cells. e-i. Chondracanthus cf. saundersii C.W. Schneid. \& C.E. Lane-e. general view of the thallus; f. detail of branching showing the curved branches; g. cross-section from basal portion of the thallus; h. cross-section from median-apical portion of the thallus; i. detail of the stellate cells between cortical and medullary portions.

se achatado acima, com até $1 \mathrm{~mm}$ de diâmetro. Ramificação irregular, alterna, oposta ou ainda unilateral, ramos frequentemente curvos e com os ápices afilados. Ramos principais e secundários apresentando numerosos râmulos curtos em toda a extensão do talo, com até $1 \mathrm{~mm}$ de comprimento.
Organização do talo multiaxial. Em corte transversal ao talo, região medular composta por filamentos dispostos frouxamente e região cortical composta por 4-5 camadas de células pequenas de formato arredondado a oval, pigmentadas. Numerosas células com formato estrelado na região de transição 
entre as células corticais e os filamentos medulares. Estruturas reprodutivas não foram encontradas.

Material examinado: Recife, Boa Viagem, estação norte, lado protegido do recife, 2.XII.2009, L.P. Soares et al. (SP 401390); Recife, Boa Viagem, estação sul, lado exposto do recife, 2.XII.2009, L.P. Soares et al. (SP 401391).

Espécie encontrada no período chuvoso, no lado exposto e protegido do embate das ondas, crescendo como epífita de Palisada perforata, Gelidium pusillum, Corallina officinalis L. e Cryptonemia seminervis (C. Agardh) J. Agardh.

Após análise conjunta de caracteres morfológicos e de sequências do gene $r b c \mathrm{~L}$, Schneider \& Lane (2005) descreveram Chondracanthus saundersii como uma espécie nova para acomodar as espécies do gênero Chondracanthus Kütz. com eixos achatados, estreitos, textura escorregadia e medula com filamentos dispostos frouxamente. Estes autores comentam que $C$. saundersii apresenta morfologia geral semelhante à de $C$. acicularis (Roth) Fredericq in Hommers. et al., mas difere desta pelas características citadas acima. Difere também de C. teedei (Mert. ex Roth) Fredericq pelo tamanho menor e eixos menos ramificados. Após essas análises, todas as espécies citadas para as Bermudas como $C$. acicularis passaram a ser identificadas como C. saundersii. Apesar de não ter sido realizada análise molecular, a observação das características morfológicas diagnósticas de C. saundersii (textura escorregadia, flácida, eixos curvos, achatados e afilados, medula formada por filamentos frouxos) em nosso material, permitiu citar a ocorrência desta espécie no litoral de Pernambuco. Cabrera et al. (2009) confirmaram a ocorrência desta espécie em Cuba, através de biologia molecular, ilustrando pela primeira vez exemplares tetrasporofíticos, mostrando que o material analisado por eles é geneticamente idêntico ao material das Bermudas, analisado por Schneider \& Lane (2005). Estes autores fizeram a primeira citação de $C$. saundersii (como Gelidium corneum (Huds.) J.V. Lamour.) para o Brasil, a partir de material coletado em 1925 na localidade de Pedra de Itapuca, Niterói (RJ). Rocha-Jorge (2010) e Silva (2011) também citam a ocorrência dessa espécie no litoral brasileiro, no Parque Estadual Laje de Santos (São Paulo) e na Área de Preservação Ambiental dos Recifes de Corais (Rio Grande do Norte), respectivamente. Estudos taxonômicos e moleculares com as espécies desse gênero no litoral brasileiro são necessários, a fim de confirmar a ocorrência de C. saundersii em outros estados.

Distribui-se no litoral brasileiro: Rio Grande do Norte (Silva 2011), São Paulo (Rocha-Jorge 2010).

\section{Florideophyceae, Ceramiales, Ceramiaceae}

Ceramium corniculatum Mont., Ann. Sci. Nat., Botanique, Série 4(14): 193-207. 1861 (1860).

Fig. 4 a-c

Talo vermelho claro, filamentoso, predominantemente prostrado, com $580 \mu \mathrm{m}$ de comprimento, dividido em nós e entrenós, fixo ao substrato por tufos de rizóides pluricelulares com extremidades simples, oriundos dos nós da porção prostrada. Eixos eretos, não ramificados, produzidos unilateralmente a cada 2 a 4 segmentos da porção prostrada. Ápices retos, afilados e ligeiramente curvos em direção ao substrato. Nós com até 15 camadas de células. Célula axial produzindo 7 células periaxiais pequenas, arredondadas, cada uma produzindo 2 células acrópetas e 2 células basípetas, que se dividem novamente até três vezes formando células acrópetas e basípetas filhas. Uma camada aparentemente sem células ocorre

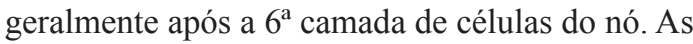
duas últimas camadas de células basípetas filhas apresentam formato alongado. Tetrasporângios tetraédricos, imersos no nó. Estruturas masculinas e femininas não foram encontradas.

Material examinado: Recife, Boa Viagem, 2.XII.2009, L.P. Soares et al. (SP 401399).

Espécie encontrada uma única vez como epífita de Gelidium pusillum, na porção apical do talo. Ocorreu no período seco e no lado protegido do embate das ondas.

Ceramium corniculatum foi citada para o Brasil pela primeira vez por Taylor (1960), em local não especificado. Nunes et al. (2008), após analisarem o sintipo de $C$. corniculatum, confirmam a presença desta espécie no litoral brasileiro, adicionando uma referência para o litoral da Bahia. Assim como os exemplares de Nunes et al. (2008), o presente material também confere com as descrições e ilustrações de $C$. corniculatum apresentadas por Littler \& Littler (2000) para o Caribe e Schneider (2004) para Bermudas.

Distribui-se no litoral brasileiro: Bahia (Nunes et al. 2008), Rio de Janeiro (Creed et al. 2010). 

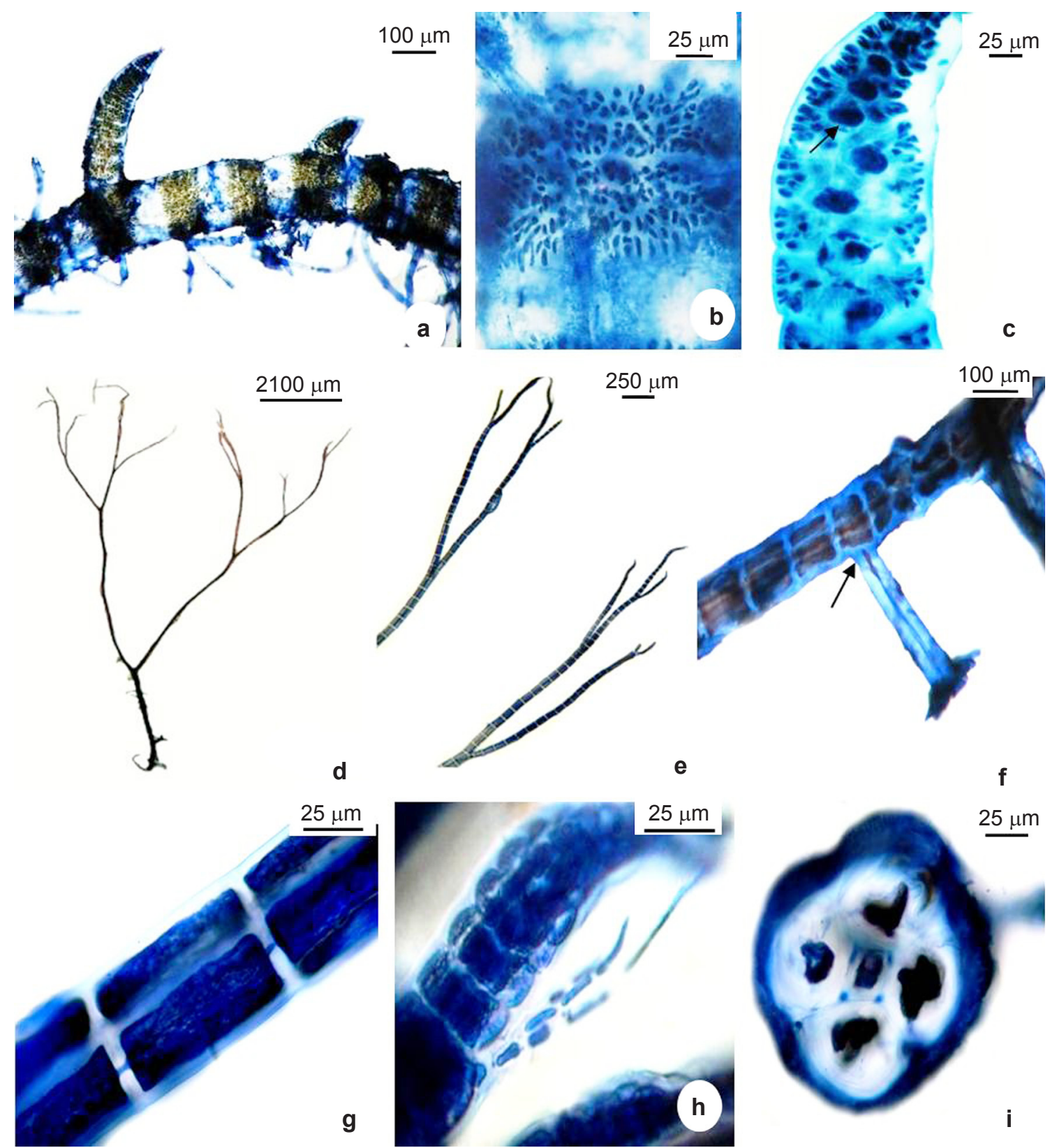

Figura 4 - Macroalgas marinhas bentônicas da praia de Boa Viagem, Recife, Pernambuco. a-c. Ceramium corniculatum Mont. - a. aspecto geral do talo, mostrando ramos eretos unilaterais; b. detalhe da corticação nodal; c. ramo portando tetrasporângios (seta). d-i. Neosiphonia sphaerocarpa (Børgesen) M.-S. Kim \& I.K. Lee - d. aspecto geral do talo; e. detalhe da ramificação; f. detalhe do rizóide com a conexão fechada (seta); g. detalhe dos segmentos mais longos que largos; h. ápice com tricoblastos; i. corte transversal da porção mediana do talo.

Figure 4 - Benthic marine macroalgae from Boa Viagem beach, Recife, Pernambuco. a-c. Ceramium corniculatum Mont. - a. general view of the thallus showing unilateral branches; b. detail of the nodal cortication; c. branch bearing tetrasporangia (arrow). d-i. Neosiphonia sphaerocarpa (Børgesen) M.-S. Kim \& I.K. Lee - d. general view of the thallus; e. detail of branching; f. detail of rhizoid with closed connection (arrow); g. detail of the segments longer than broad; h. apex with trichoblasts; i. cross-section from median portion of the thallus. 
Florideophyceae, Ceramiales, Rhodomelaceae

Neosiphonia sphaerocarpa (Børgesen) M.-S. Kim \& I.K. Lee, Phycol. Res. 47: 271-281. 1999.

Fig. 4 d-i

Talo vermelho escuro, predominantemente ereto, filamentoso, unisseriado, ecorticado, formando densos tufos sobre a macroalgasubstrato, com até $3 \mathrm{~mm}$ de comprimento e 75-90 $\mu \mathrm{m}$ de diâmetro na região mediana do talo. Talos fixos ao substrato por rizóides unicelulares proximais, com extremidades digitadas e conexão fechada (a partir da divisão da célula pericentral), oriundos de um pequeno eixo prostrado e de qualquer porção dos ramos eretos. Eixos eretos com diâmetro progressivamente menor em direção ao ápice. Ramificação alterna a subdicotômica, com um ramo da dicotomia bem mais desenvolvido que o outro, segmentos aproximadamente 2 vezes mais altos que largos. Em corte transversal da região mediana do talo, 4 células pericentrais dispostas de maneira cruciada. Tricoblastos ramificados ou não, com até 5 células, produzidos no ápice dos ramos eretos. Presença de célula-cicatriz dos tricoblastos em vários segmentos dos ramos eretos. Estruturas reprodutivas não foram observadas.

Material examinado: Recife, Boa Viagem, 29.IV.2010, L.P. Soares et al. (SP 401412).

Espécie encontrada uma única vez ao longo do estudo, como epífita de Chondracanthus $c f$. saundersii, ocorrendo no período chuvoso e no lado exposto ao embate das ondas. Guimarães et al. (2004) comentam que Neosiphonia sphaerocarpa é muito próxima de $N$. ferulacea (Suhr ex J. Agardh) S.M. Guim. \& M.T. Fujii e a separação entre essas duas espécies não é clara e que, além das dimensões do talo, as células do ostíolo do cistocarpo são caracteres de importância taxonômica. Apesar de não termos encontrado exemplares femininos, nosso material pode ser separado de $N$. ferulacea pelas dimensões do talo, critério também utilizado por Yoneshigue \& Villaça (1986), Schneider \& Searles (1991), Littler \& Littler (2000) e Mamoozadeh \& Freshwater (2011). Neosiphonia sphaerocarpa apresenta-se muito mais delicada que $N$. ferulacea, com diâmetro da região mediana do talo cerca de três vezes menor. Diâmetro do talo progressivamente menor em direção ao ápice e textura delicada, flácida, também diferenciam $N$. sphaerocarpa de $N$. ferulacea (Guimarães et al. 2004).
Distribui-se no litoral brasileiro: Rio Grande do Norte (Silva 2011), Bahia (Creed et al. 2010), Espírito Santo (Guimarães 2006), Rio de Janeiro (Yoneshigue \& Villaça 1986), São Paulo (Guimarães et al. 2004), Santa Catarina (Pupo et al. 2011).

Todas as espécies aqui registradas foram encontradas como epífitas e a maioria apresenta talo com pequenas dimensões, o que necessita de um grande esforço para analisá-las e faz com que elas sejam identificadas equivocadamente ou passem despercebidas em estudos de levantamento de flora. Das nove espécies registradas neste trabalho, quatro (Boodlea composita, Ceramium corniculatum, Chondracanthus cf. saundersii e Cladophora laetevirens) tiveram sua distribuição consideravelmente ampliada no litoral brasileiro.

Este trabalho, além de contribuir para o conhecimento da flora de macroalgas do estado de Pernambuco, acrescentou informações acerca da ficoflora epífita, confirmando a importância dessas macroalgas para a diversidade local.

\section{Agradecimentos}

À Fundação de Amparo à Ciência do Estado de Pernambuco (FACEPE), a concessão da bolsa de mestrado à primeira autora (Proc. 1418-1.08/08) . À Coordenação de Aperfeiçoamento de Pessoal de Nível Superior (CAPES), a concessão da bolsa de mestrado-sanduíche no Instituto de Botânica, SP (Proc. 077/2010). Aos Msc. Nathalia C.G. Barros, Thiago N.V. Reis e ao biólogo Edson R.T.P.P. Vasconcelos, o auxílio no trabalho de campo. Ao Conselho Nacional de Desenvolvimento Científico e Tecnológico (CNPq), a bolsa de produtividade em pesquisa para a segunda autora (Proc. 301438/2009-9). Beneficiárias do apoio financeiro da CAPES-Brasil.

\section{Referências}

Alves, A.M.; Moura, C.W.N.; Alves, G.L.A. \& Gestinari, L.M.S. 2009. Os gêneros Chaetomorpha Kütz. nom. cons. e Rhizoclonium Kütz. (Chlorophyta) do litoral do Estado da Bahia, Brasil. Revista Brasileira de Botânica 32: 545-570.

Andrade, G.O. \& Lins, R.C. 1971. Os climas do Nordeste. In: Vasconcelos Sobrinho, J. (ed.). As regiões naturais do Nordeste, o meio e a civilização. CONDEPE, Recife. Pp. 95-138.

Araújo, M.C.B.; Souza, S.T.; Chagas, A.C.O.; Barbosa, S.C.T. \& Costa, M.F. 2007. Análise da ocupação 
urbana das praias de Pernambuco, Brasil. Revista de Gestão Costeira Integrada 7: 97-104.

Azevedo, C.A.A.; Carneiro, M.A.A.; Oliveira, S.R. \& Marinho-Soriano, E. 2011. Macroalgae as an indicator of the environmental health of the Pirangi reefs, Rio Grande do Norte, Brazil. Revista Brasileira de Farmacognosia 21: 323-328.

Baptista, L.R.M. 1977. Flora ilustrada do Rio Grande do Sul. Boletim do Instituto de Biociências da Universidade Federal do Rio Grande do Sul 37: 1-248.

Brummitt, R.K. \& Powell, C.E. 1992. Authors of plant names. Royal Botanic Gardens, Kew. 732p.

Cabrera, R.; O'Shields, B. \& López-Bautista, J.M. 2009. Confirmación molecular de Chondracanthus saundersii C. W. Schneider et C. E. Lane para Cuba. Revista de Investigaciones Marinas 30: 85-89.

Câmara Neto, C. 1971. Primeira contribuição ao inventário das algas marinhas bentônicas do litoral do Rio Grande do Norte. Boletim de Biologia Marinha 5: 127-154.

Coto, A.C.S.P. \& Pupo, D. 2009. Ulvophyceae. Rima, São Carlos. 86p.

Creed, M.F.; Fujii, M.T.; Barreto, M.B.B.; Guimarães, S.M.P.B.; Cassano, V.; Pereira, S.M.B.; Carvalho, M.F.O. \& Khader, S. 2010. Rhodophyceae. In: Forzza, R.C. et al. (orgs). Catálogo de plantas e fungos do Brasil. Andrea Jakobsson Estúdio, Instituto de Pesquisas Jardim Botânico do Rio de Janeiro, Rio de Janeiro. Pp. 416-436.

De Clerck, O.; Bolton, J.J.; Anderson, R.J. \& Coppejans, E. 2005. Guide to the seaweeds of KwaZulu-Natal. Scripta Botanica Belgica 33: 1-294.

Dias Filho, M.J.O.; Araújo, M.C.B.; Silva-Cavalcanti, J.S. \& Silva, A.C.M. 2011. Contaminação da praia de Boa Viagem (Pernambuco-Brasil) por lixo marinho: relação com o uso da Praia. Arquivos de Ciências do Mar 44: 33-39.

Dominguez, J.M.L.; Bittencourt, A.C.S.P.; Leão, Z.M.A.N. \& Azevedo, A.E.G. 1990. Geologia do quaternário costeiro do estado de Pernambuco. Revista Brasileira de Geociências 20: 208-215.

Falcão, C.; Maurat, M.C.; Nassar, C.A.G.; Széchy, M.T.M. \& Mitchell, G.J.P. 1992. Benthic marine flora of the Northeastern and Southeastern coast of Ilha Grande, Rio de Janeiro, Brazil: phytogeographic considerations. Botanica Marina 35: 357-364.

Ferreira-Correia, M.M.; Lopes, M.J.S. \& Brandão, M.D.S. 1977. Levantamento das algas marinhas bentônicas da Ilha de São Luís (estado do Maranhão, Brasil). Boletim do Laboratório de Hidrobiologia 1: 23-46.

Gestinari, L.M.S.; Nassar, C.A.G. \& Arantes, P.V. 1998. Algas marinhas bentônicas da Reserva Biológica Estadual da Praia do Sul, Ilha Grande, Angra dos Reis, Rio de Janeiro, Brasil. Acta Botanica Brasilica 12: 67-76.
Gregório, M.N. \& Araújo, T.C.M. 2008. Interannual morphological changes of Boa Viagem beachNortheast coast of Brazil. Boletim Paranaense de Geociências 62/63: 61-84.

Guimarães, S.M.P.B. 2006. A revised checklist of benthic marine Rhodophyta from the state of Espírito Santo, Brazil. Boletim do Instituto de Botânica 17: 143-194.

Guimarães, S.M.P.B.; Fujii, M.T.; Pupo, D. \& Yokoya, N.S. 2004. Reavaliação das características morfológicas e suas implicações no gênero Polysiphonia sensu lato (Ceramiales, Rhodophyta) do litoral dos Estados de São Paulo e Espírito Santo, Brasil. Revista Brasileira de Botânica 27: 163-183.

Hoek, C. van den. 1982. A taxonomic revision of the american species of Cladophora (Chlorophyceae) in the North Atlantic Ocean and their geographic distribution. Verhandelingen der Koninklijke Nederlandse Akademie van Wetenschappen, Afdeling Natuurkunde, Tweede Reeks 78: 1-236.

Hoek, C. van den; Mann, D.G. \& Jahns, H.M. 1995. Algae: an introduction to phycology. Cambridge University Press, Cambridge. 623p.

Horta, P.A.; Amancio, E.; Coimbra, C.S. \& Oliveira, E.C. 2001. Considerações sobre a distribuição e origem da flora de macroalgas marinhas brasileiras. Hoehnea 28: 243-265.

Howe, M.A. 1928. Notes on some marine algae from Brazil and Barbados. Journal of the Washington Academy of Sciences 18: 186-194.

Huff, T.M. 2011. Effects of human trampling on macro- and meiofauna communities associated with intertidal algal turfs and implications for management of protected areas on rocky shores (Southern California). Marine Ecology. doi: 10.1111/j.1439-0485.2011.00467.x

Kempf, M. 1967/69. A plataforma continental de Pernambuco (Brasil): nota preliminar sobre a natureza do fundo. Trabalhos Oceanográficos da Universidade Federal de Pernambuco 9/11: 111-124.

Leliaert, F. \& Coppejans, E. 2004. Crystalline cell inclusions: a new diagnostic character in the Cladophorophyceae (Chlorophyta). Phycologia 43: 189-203.

Leliaert, F. \& Coppejans, E. 2007. Morphological reassessment of the Boodlea composita-Phyllodictyon anastomosans species complex (Siphonocladales: Chlorophyta). Australian Systematic Botany 20: 161-185.

Leliaert, F.; De Clerck, O.; Verbruggen, H.; Boedecker, C. \& Coppejans, E. 2007b. Molecular phylogeny of the Siphonocladales (Chlorophyta: Cladophorophyceae). Molecular Phylogenetics and Evolution 44: 1237-1256.

Leliaert, F.; Huisman, J.M. \& Coppejans, E. 2007a. Phylogenetic position of Boodlea vanbosseae 
(Siphonocladales, Chlorophyta). Cryptogamie, Algologie 28: 337-351.

Leliaert, F.; Rousseau, F.; de Reviers, B. \& Coppejans, E. 2003. Phylogeny of the Cladophorophyceae (Chlorophyta) inferred from partial LSU rRNA gene sequences: is the recognition of separate order Siphonocladales justified? European Journal of Phycology 38: 233-246.

Littler, D.S. \& Littler, M.M. 2000. Caribbean reef plants: an identification guide to the reef plants of the Caribbean, Bahamas, Florida and Gulf of Mexico. Offshore Graphics, Washington, 542p.

Mamoozadeh, N.R. \& Freshwater, D.W. 2011. Taxonomic notes on Caribbean Neosiphonia and Polysiphonia (Ceramiales, Florideophyceae): five species from Florida, USA and Mexico. Botanica Marina 54: 269-292.

McNeill, J.F.R.; Barrie, F.R.; Burdet, H.M.; Demoulin, V.; Hawksworth, D.L.; Marhold, K.; Nicolson, D.H.; Prado, J.; Silva, P.C.; Skog, J.E. \& Wiersema, J.H. (eds). 2006. International Code of Botanical Nomenclature (Vienna Code), adopted by the Seventeenth International Botanical Congress, Vienna, Austria, July 2005. Disponível em <http:// ibot.sav.sk/icbn/main.htm>. Acesso em 18 Ago 2011.

Monteiro Neto, C. \& Mendonça Neto, J.P. 2009. Biologia da conservação marinha. Pp. 579-610. In: Pereira, R.C. \& Soares-Gomes, A. (orgs). Biologia marinha. 2 ed. Interciência, Rio de Janeiro.

Moura, C.W.N. 2010. Ulvophyceae. In: Forzza, R.C. et al. (orgs.). Catálogo de plantas e fungos do Brasil. Instituto de Pesquisas Jardim Botânico do Rio de Janeiro, Rio de Janeiro. Pp. 438-448.

Nassar, C.A.G. 1994. An assessment to the benthic marine algae at Trindad Island, Espírito Santo, Brazil. Revista Brasileira de Biologia 54: 623-629.

Nunes, J.M.C. 1998. Catálogo de algas marinhas bentônicas do Estado da Bahia, Brasil. Acta Botanica Malacitana 23: 5-21.

Nunes, J.M.C.; Barros-Barreto, M.B. \& Guimarães, S.M.P.B. 2008. A família Ceramiaceae (Ceramiales, Rhodophyta) no estado da Bahia, Brasil. Monografias Ficológicas 3: 75-159.

Oliveira Filho, E.C. 1977. Algas marinhas bentônicas do Brasil. Tese de Livre Docência. Universidade de São Paulo, São Paulo. 477p.

Pereira, S.M.B.; Oliveira-Carvalho, M.F.; Angeiras, J.A.P.; Oliveira, N.M.B.; Torres, J.; Gestinari, L.M.S.; Bandeira-Pedrosa, M.E.; Cocentino, A.L.M.; Santos, M.D.; Nascimento, P.R.F. \& Cavalcanti, D.R. 2002. Algas marinhas bentônicas do estado de Pernambuco. In: Tabarelli, M. \& Silva, J.M. (eds.). Diagnóstico da Biodiversidade de Pernambuco. Massangana/ Secretaria de Ciência, Tecnologia e Meio Ambiente, Recife. Pp. 97-124.
Pinheiro-Joventino, F.; Dantas, N.P. \& Maraschin, C.H.D. 1998. Distribuição de algas marinhas no litoral de Fortaleza. Arquivo de Ciências do Mar 31: 29-40.

Pupo, D.P.; Ouriques, L.C.; Fujii, M.T.; Guimarães, S.M.P.B. \& Yokoya, N.S. 2011. Marine benthic algae from Santa Catarina state, Southern Brazil. Boletim do Instituto de Botânica 20: 1-112.

Rocha-Jorge, R. 2010. Diversidade de macroalgas do Parque Estadual Marinho da Laje de Santos, SP, Brasil. Dissertação de Mestrado. Instituto de Botânica, São Paulo. 177p.

Rollnic, M. \& Medeiros, C. 2006. Circulation of the coastal waters off Boa Viagem, Piedade and Candeias beaches, Pernambuco, Brazil. Journal of Coastal Research 39: 648-650.

Rollnic, M.; Medeiros, C. \& Freitas, I. 2011. Coastal circulation along the southern metropolitan region of Recife, Northeastern Brazil. Journal of Coastal Research 64: 135-138.

Schneider, C.W. 2004. Notes on the marine algae of the Bermudas, 6: Some rare or newly reported Ceramiales (Rhodophyta), including Crouania elisiae sp. nov. Phycologia 43: 563-578.

Schneider, C.W. \& Lane, C.E. 2005. Notes on the marine algae of the Bermudas, 7: Additions to the flora including Chondracanthus saundersii sp. nov. (Rhodophyta, Gigartinaceae) based on $r b c \mathrm{~L}$ sequence analysis. Phycologia 44: 72-83.

Schneider, C.W. \& Searles, R.B. 1991. Seaweeds of the southeastern United States: Cape Hatteras to Cape Canaveral. Duke University Press, Durham, London. 553p.

Silva, I.B. 2011. Algas marinhas bentônicas de Maracajaú, Área de Preservação Ambiental dos Recifes de Corais, Rio Grande do Norte, Brasil. Tese de Doutorado. Instituto de Botânica, São Paulo. 348p.

Silva, J.S.S.; Barbosa, S.C.T.; Leal, M.M.V.; Lins, A.R. \& Costa, M.F. 2006. Ocupação da praia de Boa Viagem (Recife/PE) ao longo de dois dias de verão: um estudo preliminar. Pan-American Journal of Aquatic Sciences 1: 91-98.

Silva, J.S.S.; Leal, M.M.V.; Araújo, M.C.B.; Barbosa, S.C.T. \& Costa, M.F. 2008. Spatial and temporal patterns of use of Boa Viagem beach, Northeast Brazil. Journal of Coastal Research 24: 79-86.

Simões, I.P.; Guimaraens, M.A.; Oliveira-Carvalho, M.F.; Valdevino, J. \& Pereira, S.M.B. 2009. Avaliação florística e sucessão ecológica das macroalgas em recifes na Praia de Piedade (PE). Neotropical Biology and Conservation 4: 49-56.

Sousa, G.S. \& Cocentino, A.L.M. 2004. Macroalgas como indicadoras da qualidade ambiental da Praia de Piedade, PE. Tropical Oceanography 32: 1-22. 
Széchy, M.T.M.; Nassar, C.A.G.; Falcão, C. \& Maurat, M.C.S. 1989. Contribuição ao inventário das macroalgas bentônicas do Arquipélago de Fernando de Noronha. Nerítica 2: 135-146.

Taylor, W.R. 1960. Marine algae of the eastern tropical and subtropical coasts of the Americas. University of Michigan Press, United States. 869p.

Ugadim, Y. 1973. Algas marinhas bentônicas do litoral sul do estado de São Paulo e do litoral do estado do Paraná, I - Divisão Chlorophyta. Boletim de Botânica da Universidade de São Paulo 1: 11-77.

Villaça, R.; Pedrini, A.G.; Pereira, S.M.B. \& Figueiredo, M.A.O. 2006. Flora marinha bentônica das ilhas oceânicas brasileiras. In: Alves, R.J.V. \& Costa, J.W. (orgs.). Ilhas oceânicas brasileiras: da pesquisa ao manejo. Ministério do Meio Ambiente, Brasília. Pp. 107-146.

Wynne, M.J. 2011. A checklist of benthic marine algae of the tropical and subtropical Western Atlantic: third revision. Nova Hedwigia 140: 1-166.
Yoneshigue, Y.; Boudouresque, C.F. \& Figueiredo, M.A.O. 1986. Flore algale marine de la région de Cabo Frio, état de Rio de Janeiro (Brésil), 5: Sur Boodlea composita (Boodleaceae - Chlorophyta), Dictyota pardalis (Dictyotaceae - Phaeophyta) et Lophosiphonia cristata (Rhodomelaceae Rhodophyta), espèces nouvelles pour la cote brésilienne. Rickia 13: 17-27.

Yoneshigue, Y. \& Villaça, R.C. 1986. Flora marinha da região de Cabo Frio, estado do Rio de Janeiro, Brasil, 6: Pterosiphonia spinifera, Polysiphonia eastwoode, P. flaccidissima, P. sphaerocarpa e Streblocladia corymbifera (Rhodomelaceae, Rhodophyta), novas ocorrências para a costa brasileira. Rickia 13: 97-111.

Yoneshigue-Valentin, Y.; Gestinari, L.M.S. \& Fernandes, D.R.P. 2006. Macroalgas. In: Lavrado, H.P. \& Ignacio, B.L. (orgs.). Biodiversidade bentônica da região central da Zona Econômica Exclusiva Brasileira. Museu Nacional, Rio de Janeiro. Pp. 67-105. 